\section{Professionals make joint plea to Chancellor over NHS and social care funding}

Dentists' representatives along with most of the NHS professions have made a joint plea to Chancellor Philip Hammond to use his forthcoming autumn budget to deliver long-term investment in the NHS workforce, public health services and adult social care.

A coalition of 11 royal colleges and health faculties sent a letter ${ }^{1}$ on 16 October 2018 to Hammond saying that without this investment, there was a real risk the NHS would fail to meet demands despite the recent $£ 20.5$ billion funding increase announced in the summer.

The letter was signed jointly by the Royal College of Physicians, Royal College of Surgeons of Edinburgh (including the Faculty of Dental Surgery), Royal College of Surgeons, Royal College of Anaesthetists, Royal College of Psychiatrists, Royal College of Nursing, Royal Pharmaceutical Society, Royal College of Emergency Medicine, Faculty of Public Health and Faculty of Sexual and Reproductive Healthcare.

The signatories warn that unless the autumn budget is used as an opportunity to build upon the NHS funding settlement, plans for truly integrated care will not be possible and consequent demand on NHS services will not be manageable.

'There is no excuse for delay', says the letter. 'Once again we face a winter of high bed occupancy and low staff morale, which an injection of adult social care funding will significantly alleviate.'

The letter also says a healthier population is critical to the long-term sustainability of all public services, including NHS and social care services, and concludes: 'We can no longer afford to plan and fund health and care services in isolation. A stronger strategy to make sure we live both long and healthy lives must start now?

1. Joint Letter to Chancellor Philip Hammond (16 October 2018). https://www.rcsed.ac.uk/ media/417309/autumn-budget-letter.pdf. (accessed on 22 October 2018).

\title{
Air pollution exposure may be linked to higher risk of mouth cancer
}

High levels of small particles $\left(\mathrm{PM}_{2.5}\right)$ in air pollution appear to be linked to a $43 \%$ greater chance of developing mouth cancer, according to a recent study ${ }^{1}$ published online in the Journal of Investigative Medicine.

Researchers from Asia University and Chung Shan Medical University in Taiwan found an association between air pollution levels and cancer.

The study comes as this year's Mouth Cancer Action Month running throughout November was launched by the Oral Health Foundation and the Mouth Cancer Foundation.

Each year, around 7,800 new cases of mouth and oropharyngeal cancer are diagnosed in the UK. Both the number of new cases and deaths from mouth cancer are increasing in many parts of the world and known risk factors include smoking, drinking, human papilloma virus, and in parts of South East Asia, the chewing of betel quid ('paan') - a mix of ingredients wrapped in betel leaf.

Exposure to heavy metals and emissions from petrochemical plants are also thought to be implicated in the development of the disease, while air pollution, especially $\mathrm{PM}_{2.5}$, is known to be harmful to respiratory and cardiovascular health.

To find out if air pollutants might have a role in the development of mouth cancer, the researchers mined national cancer, health, insurance, and air quality databases.

They drew on average levels of air pollutants (sulphur dioxide, carbon monoxide, ozone, nitrogen monoxide, nitrogen dioxide, and varying sizes of fine particulate matter), measured in 2009 at 66 air quality monitoring stations across Taiwan.

In 2012-13, they checked the health records of 482,659 men aged 40 and older who had attended preventive health services and who had provided information on smoking/betel quid chewing.

Diagnoses of mouth cancer were then linked to local area readings for air pollutants taken in 2009.

Results showed that in 2012-13, 1,617 cases of mouth cancer were diagnosed among the men. Smoking and frequent betel quid chewing were significantly associated with heightened risk of a diagnosis. However, so too were high levels of $\mathrm{PM}_{2.5}$.

When compared with particulate matter levels below $26.74 \mu \mathrm{g} / \mathrm{m}^{3}$ (micrograms per cubic metre), those above $40.37 \mu \mathrm{g} / \mathrm{m}^{3}$ were associated with a $43 \%$ heightened risk of a mouth cancer diagnosis.

Even though this was an observational study, so the researchers could not establish cause, they concluded: 'This study, with a large sample size, is the first to associate oral cancer with $\mathrm{PM}_{2.5}$. These findings add to the growing evidence on the adverse effects of $\mathrm{PM}_{2.5}$ on human health.'

It was unclear how air pollutants might contribute to mouth cancer, they acknowledged, saying that further research was needed to explore this.

The organisers of this year's Mouth Cancer Action Month (www.mouthcancer.org) said this form of the disease caused more deaths per number of cases than breast cancer, cervical cancer or melanomas and that around 60,000 people would be diagnosed with mouth cancer over the next decade.

Tobacco use was still considered the main cause of mouth cancer but drinking alcohol to excess could increase the risk of mouth cancer fourfold, meaning that people who smoke and drank were up to 30 times more likely to develop mouth cancer.

Chief Executive of the Oral Health Foundation, Dr Nigel Carter, urged dentists to raise awareness of the disease and communicate the importance of early detection, saying: 'Mouth cancer is one of the few cancers which continues to see the number of cases increase.

'The number of people being diagnosed with the disease has grown by more than a third over the last decade. Being on the frontline in the fight against mouth cancer, your support for campaigns like Mouth Cancer Action Month are crucial. By being 'Mouthaware' and spotting mouth cancer early enough, we can give patients the best possible chance to beat mouth cancer and have a good quality of life'

1. Chu Y, Kao S, Tantoh D M, Ko P, Lan S, Liaw Y. Association between fine particulate matter and oral cancer among Taiwanese men (9 October 2018). J Invest Med 2018; DOI: 10.1136/jim-2016-000263. https://jim. bmj.com/content/early/2018/08/13/jim-2016-000263 (accessed 23 October 2018). 